九州大学学術情報リポジトリ

Kyushu University Institutional Repository

\title{
Vibration Analysis of the Forced Vibration Experiment for the Riding Tractor
}

Noguchi, Ryozo

Laboratory of Agricultural machinery, Faculity of Agriculture, Kyushu University

Inoue, $\mathrm{Eij} \mathrm{i}$

Laboratory of Agricultural machinery, Faculity of Agriculture, Kyushu University

Kinoshita, Osamu

Laboratory of Agricultural machinery, Faculity of Agriculture, Kyushu University

Sakai, Jun

Laboratory of Agricultural machinery, Faculity of Agriculture, Kyushu University

https://doi.org/10.5109/24045

出版情報：九州大学大学院農学研究院紀要. 38 (1/2)，pp.127-136，1993-12. Kyushu University バージョン：

権利関係 : 


\title{
Vibration Analysis of the Forced Vibration Experiment for the Riding Tractor
}

\author{
Ryozo Noguc hi *, Eiji Inoue, Osamu Kinoshita \\ and Jun Sakai \\ Laboratory of Agricultural machinery, Faculity of Agriculture, \\ Kyushu University 46-05, Fukuoka 812, Japan \\ (Received August 1, 1993)
}

\begin{abstract}
In the forced vibration experiment of the riding tractor, the time continuous data of the acceleration were analyzed by spectrum map, phase projection and Poincare section to examine the linearity or nonlinearity characterisitics for dynamic behavior of the tractor. Spectrum map and phase projection of the acceleration in the forward and the vertical direction at the center of gravity of the tractor showed some nonlinearity at the forced friquency ranging from $8.0 \mathrm{~Hz}$ to $10.0 \mathrm{~Hz}$, and Poincare section indicated the periodicity for all accelerations. The result suggested that the nonlinear elements of the tractor didn't affect the vibration characteristics of it at the forced frequency ranging from $1.0 \mathrm{~Hz}$ to $5.0 \mathrm{~Hz}$, but greatly affected at forced frequency greater than $8.0 \mathrm{~Hz}$.
\end{abstract}

\section{INTRODUCTION}

Periodical vibration force of the tractor with rotary tiller, which mainly is used in paddy rice fields in Asia, is transmitted from the rotary shaft in cultivation. From the viewpoint of human engineering (Goldman and Gierk, 1960), the dynamic model of the tractor with the rotary tiller was solved using linear differential equations to enable quantitative analysis of the tractor's vibration, and the frequency response functions for these differential equations were obtained (Collins, 1991; Sakai et al., 1991). So we performed the forced vibration experiment on the artificial field to prove the validity of the dynamic model of a riding tractor with rotary tiller (Fig. 1).

This paper deals with analysis of the acceleration in the forced vibration experiment by using the spectum map, phase projection and Poincare section, and discussion of the vibration characteristics of the tractor.

\section{EXPERIMENTATION}

\section{Experiment and measurement apparatus}

An illustration of the forced vibration experiment for the riding tractor with rotary tiller is shown in Fig. 2. The forced shaker can transmit the artificial vibration force to the tractor in order to simulate the periodical vibration force that occers from a rotary tiller in cultivation. The forced shaker consists of a driving unit, eccentric \& slider

\footnotetext{
*Present address: Institute of Agricultural and Forest Engineering, University of

Tsukuba,Tennodai, Tsukuba, Ibaraki, 305 Japan
} 
Table 1. Parameters for the forced vibration experiment.

\begin{tabular}{c|c||c|c}
\hline$\theta$ & $\mathbf{4 3}$ & $\mathrm{H}$ & $-0.274 \mathrm{~m}$ \\
$\mathrm{~L}_{1}$ & $1.036 \mathrm{~m}$ & $\mathrm{~h}_{R}$ & $0.240 \mathrm{~m}$ \\
$\mathrm{~L}_{\mathrm{G}}$ & $0.406 \mathrm{~m}$ & $\mathrm{k}_{1}$ & $300000 \mathrm{~N} / \mathrm{m}$ \\
$\mathrm{L}_{3}$ & $0.850 \mathrm{~m}$ & $\mathrm{k}_{2}$ & $700000 \mathrm{~N} / \mathrm{m}$ \\
$\mathrm{L}_{4}$ & $0.406 \mathrm{~m}$ & $\mathrm{k}_{3}$ & $600000 \mathrm{~N} / \mathrm{m}$ \\
$\mathrm{L}_{\mathrm{R}}$ & $0.000 \mathrm{~m}$ & $\mathrm{k}_{4}$ & $\mathrm{ON} / \mathrm{m}$ \\
$\mathrm{e}_{1}$ & $0.000 \mathrm{~m}$ & $\mathrm{c}_{1}$ & $250 \mathrm{~N} \cdot \mathrm{s} / \mathrm{m}$ \\
$\mathrm{e}_{2}$ & $0.000 \mathrm{~m}$ & $\mathrm{c}_{2}$ & $1800 \mathrm{~N} \cdot \mathrm{s} / \mathrm{m}$ \\
$\mathrm{h}_{1}$ & $0.248 \mathrm{~m}$ & $\mathrm{c}_{3}$ & $1800 \mathrm{~N} \cdot \mathrm{s} / \mathrm{m}$ \\
$\mathrm{h}_{2}$ & $0.480 \mathrm{~m}$ & $\mathrm{c}_{4}$ & $0 \mathrm{~N} \cdot \mathrm{s} / \mathrm{m}$ \\
$\mathrm{h}_{4}$ & $0.375 \mathrm{~m}$ & $\mathrm{~m}$ & $849.536 \mathrm{~kg}$ \\
$\mathrm{~h}_{G}$ & $0.649 \mathrm{~m}$ & $\mathrm{i}_{G}$ & $357.279 \mathrm{~kg} \cdot \mathrm{m}^{2}$ \\
\hline
\end{tabular}

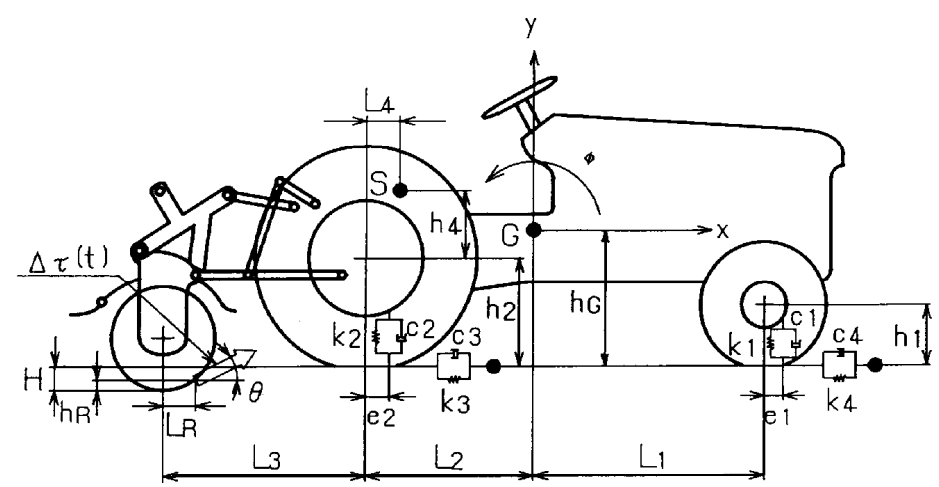

Fig. 1. Dynamic model of a riding tractor with rotary tiller.

mechanisms, and shock absorbers. At the first stage, the driving unit rotates the eccentric \& slider mechanisms by an electric motor. At the second stage, the reciprocating motion of the eccentric \& slider mechanisms is transformed into the vibration force through the shock absorbers. Finally, the vibration force is transmitted to the rotary tiller of the tractor. A small-size riding tractor $(11.2 \mathrm{~kW})$ was used in our experiment.

Accelerometers of the $5 \mathrm{G}$ type ( $\mathrm{G}$; gravitational constant) were mounted on the tractor to measure the tractor's vibration. A three-dimensional accelerometer was set on the center of gravity of the tractor to measure the vibration in the forward and vertical direction, and two accelerometers were set on the front and rear of the tractor to measure the vibration in the piching direction. The load cells were set on the top of the shock absorbers to measure the vibration force.

The accelerations and the vibration forces were recorded by a multi-channel recorder according to the forced frequency stepped by $0.1 \mathrm{~Hz}$ between $1.0 \mathrm{~Hz}$ and $10.0 \mathrm{~Hz}$. The data which were obtained from the forced vibration experiment at a forced angle of 43 " are discussed in the paper. 


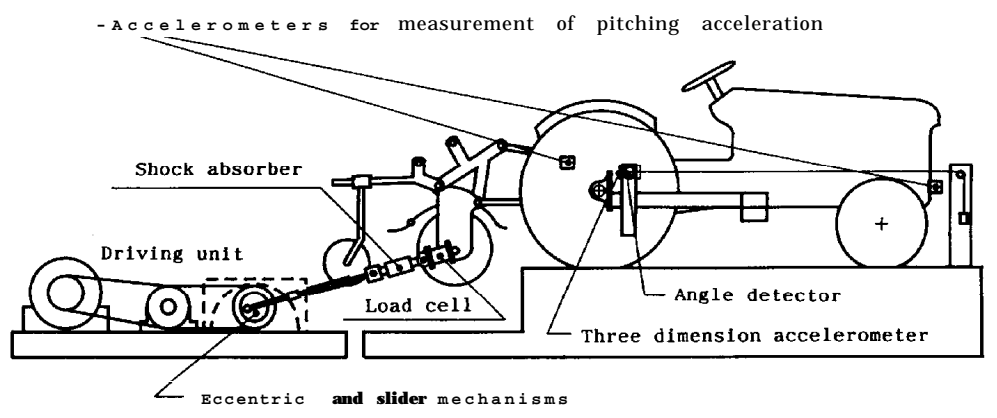

Fig. 2. Illustration of the forced shaker and the forced vibration experiment of the riding tractor.

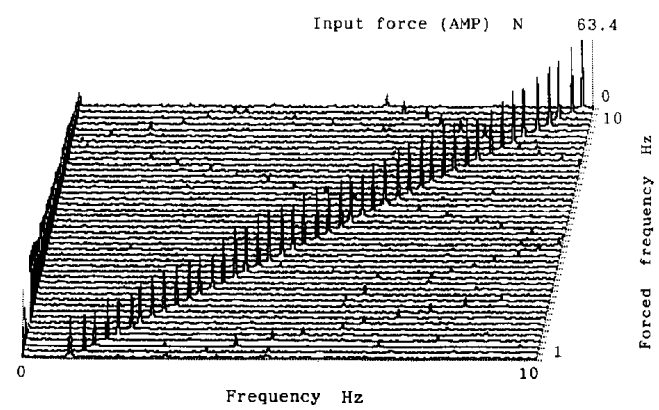

Fig. 3. Spectrum map of the vibration force for the left side (forced angle $43^{\circ}$, rms value).

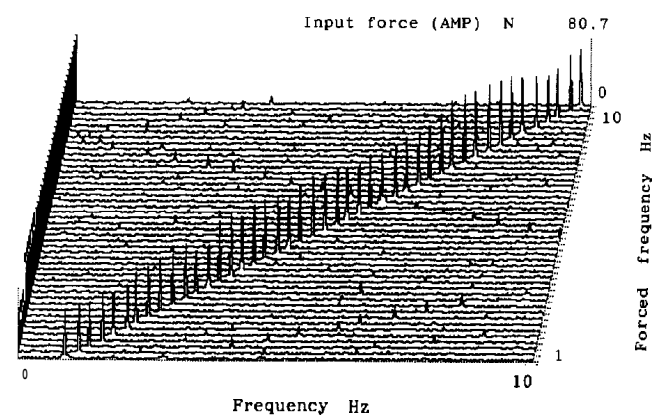

Fig. 4. Spectrum map of the vibration force for the right side (forced angle $43^{\circ}$, rms value).

\section{Analysis method}

The data of the experiment were analyzed by using an FFT analyzer for spectrum map, phase projection and Poincare section by using the A/D converter and personal computer.

At the first stage, the spectrum maps for two vibration forces and three accelerations were drawn (Fig. 3 8). The longitudinal axis of each figure shows the frequency of the tractor's vibration, the lateral axis shows the forced frequency, and the vertical axis shows the amplifier (rms value) of the vibration force or the acceleration.

At the second stage, the time continuous data of the acceleration were plotted on 


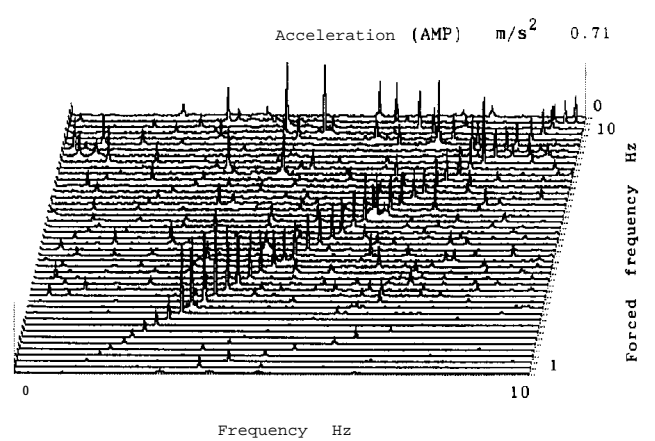

Fig. 5. Spectrum map of the acceleration in the forward direction at the tractor's center of gravity (x-direction), (forced angle $43^{\circ}$, rms value).

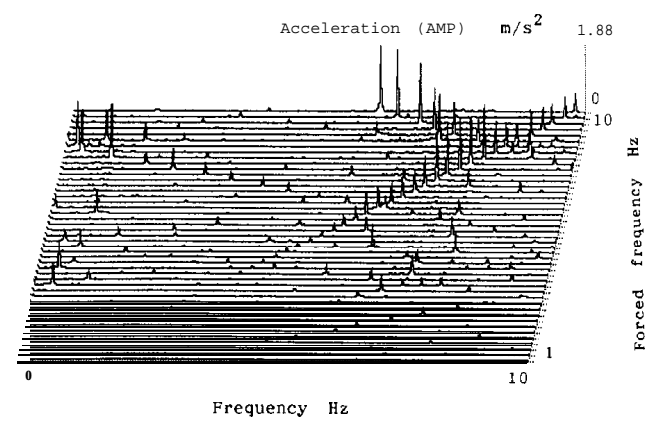

Fig. 6. Spectrum map of the acceleration in the vertical direction at the tractor's center of gravity (y-direction), (forced angle $43^{\circ}$, rms value).

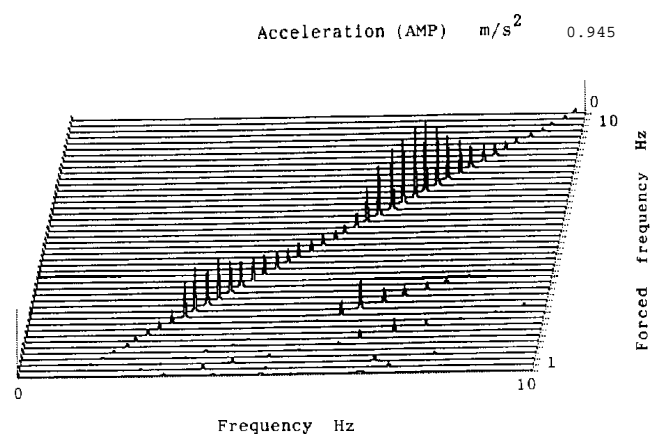

Fig. 7. Spectrum map of the acceleration in the vertical direction at the tractor's front end (forced angle $43^{\circ}$, rms value).

the computer screen by using analysis method of phase projection and Poincare section, and some typical figures are shown in Fig. 9 14. The method is always used to analyze the chaotic behavior (Thompson and Stewart, 1988; Dimarogonas and Haddad, 1992). In this paper, the unit of horizontal axis and vertical axis for phase projection and Poincare section is acceleration $\left(\mathrm{m} / \mathrm{s}^{2}\right)$. If $\mathrm{R}(\mathrm{t})$ expresses the time continuous data, then a horizontal position of the data on the phase projection plane is given by $\mathrm{R}(\mathrm{t})$, and a vertical position of it is given by $\mathrm{R}(\mathrm{t}+\tau)$. The parameter $\tau$ which expresses a delay 


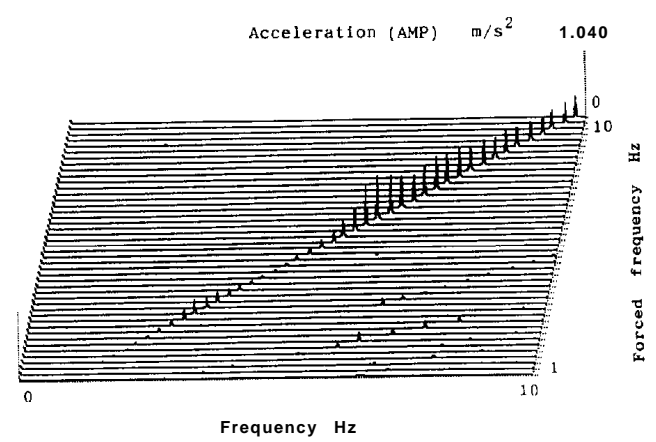

Fig. 8. Spectrum map of the acceleration in the vertical direction at the tractor's rear end (forced angle $43^{\circ}$,rms value).

time from $\mathrm{t}$ cannot be decided (Thompson and Stewart, 1988). However, if the data were given from the system whose behavior was effected by the continuous and regular vibration force, then $\tau$ is given as T/4 (T; forced vibration period) (Kenshi Sakai et al., 1992).

The reason that $\tau$ is given as T/4 can be explained as follows. If the time continuous data $R(t)$ is given as data including only a frequency $(\omega / 2 \pi), R(t)$ is expressed as follows;

$$
\mathrm{R}(\mathrm{t})=\sin (\omega \mathrm{t}+\Phi)
$$

$$
\begin{aligned}
& \text { A : amplitude } \\
& \Phi: \text { phase angle }
\end{aligned}
$$

then $\tau$ is given as $\mathrm{T} / 4$,

$$
\begin{aligned}
\mathrm{T} & =\frac{2 \pi}{\omega} \\
\therefore \quad \tau & =\frac{\pi}{2 \omega}
\end{aligned}
$$

and,

$$
\begin{aligned}
\mathrm{R}(\mathrm{t}+\tau) & =\mathrm{A} \sin \{\omega(\mathrm{t}+\tau)+\Phi\} \\
& =\mathrm{A} \sin \left(\omega+\frac{\pi}{2}+\Phi\right) \\
& =\mathrm{A} \cos (\omega \mathrm{t}+\Phi) .
\end{aligned}
$$

So a figure of phase projection is given as a circle described by the following equation,

$$
R^{2}(t)+R^{2}(t+\tau)=A^{2}
$$

Poincare section is obtained from the phase projection according to the regular period of the forced vibration. So a horizontal position of the time continuous data on the Poincare section is given by $\mathrm{R}(\mathrm{t}+\mathrm{nT})$ ( $\mathrm{n}$; natural number), and a vertical position of it is given by $\mathrm{R}(\mathrm{t}+\boldsymbol{\tau}+\mathrm{nT})$. If data has a periodicity based on the forced frequency, the 


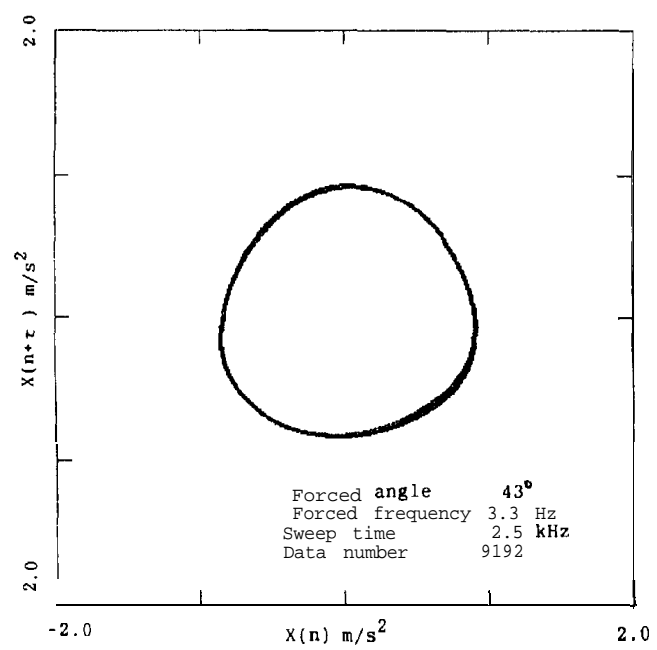

Fig. 9. Phase projection of the acceleration in the forward direction at the tractor's center of gravity (x-direction), (forced angle $43^{\circ}$, forced frequency $3.3 \mathrm{~Hz}$ ).

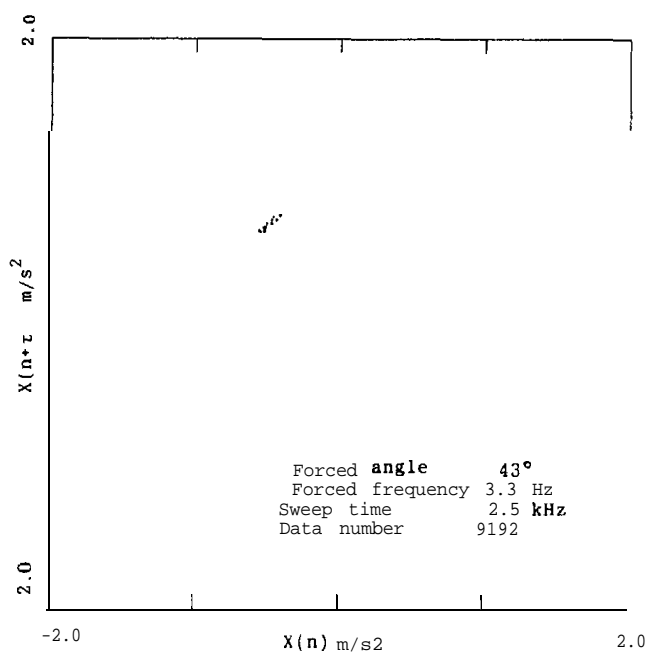

Fig. 10. Poincare section of the acceleration in the forward direction at the tractor's center of gravity (x-direction), (forced angle $43^{\circ}$, forced frequency $3.3 \mathrm{~Hz}$ ).

figure of a phase projection is a circle or an ellipse, and the figure of Poincare section shows the plotted points gathered on a very small area.

All acceleration of the experiment were plotted on phase projection and Poincare section through the low-pass filter (less than $10.0 \mathrm{~Hz}$ ) and $\mathrm{A} / \mathrm{D}$ converter in our analysis method. Sweep time was $2.5 \mathrm{kHz}$, and the number of discrete data plotted on our plane of phase projection was 8192 . 


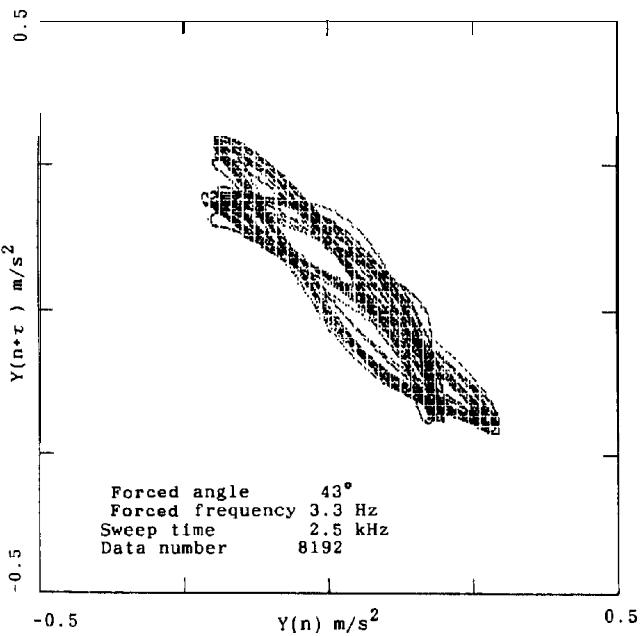

Fig. 11. Phase projection of the acceleration in the vertical direction at the tractor's center of gravity (y-direction), (forced angle $43^{\circ}$, forced frequency $3.3 \mathrm{~Hz}$ ).

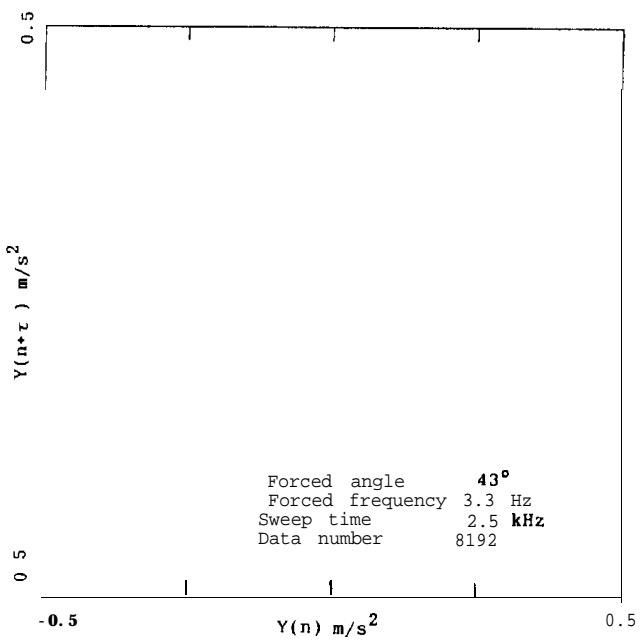

Fig. 12. Poincare section of the acceleration in the vertical direction at the tractor's center of gravity (y-direction), (forced-angle $43^{\circ}$, forced frequency $3.3 \mathrm{~Hz}$ ).

\section{RESULTS AND DISCUSSIONS}

\section{Spectrum map}

Spectrum map of the vibration force for the left side (Fig. 3) and the spectrum map for the right side (Fig. 4) showed that each spectrum of the vibration force at the forced frequency ranging from $1.0 \mathrm{~Hz}$ to $10.0 \mathrm{~Hz}$ had one clear amplifier peak according to the forced frequency. The deviation of the vibration force on each side was nearly 


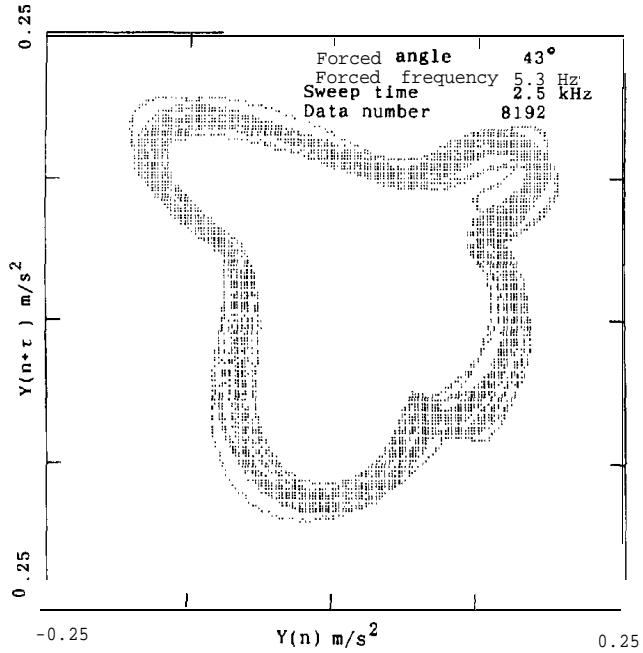

Fig. 13. Phase projection of the acceleration in the vertical direction at the tractor's center of gravity (y-direction), (forced angle $43^{\circ}$, forced frequency $5.3 \mathrm{~Hz}$ ).

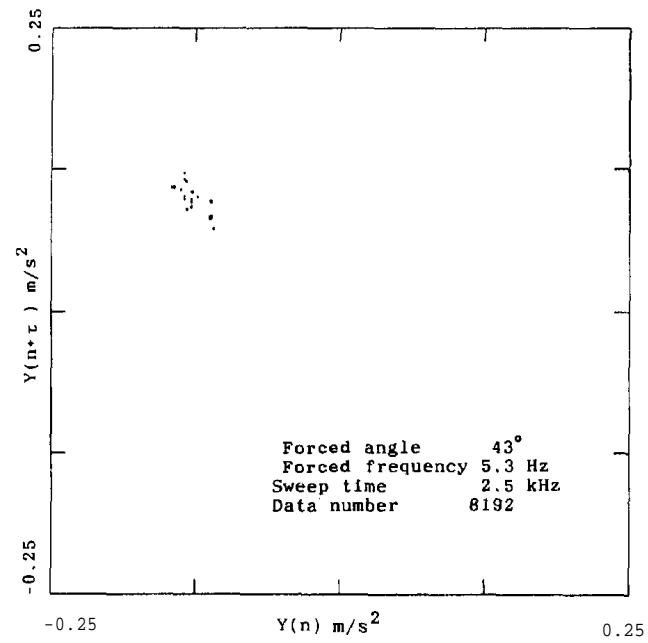

Fig. 14. Poincare section of the acceleration in the vertical direction at the tractor's center of gravity (y-direction), (forced angle $43^{\circ}$, forced frequency $5.3 \mathrm{~Hz}$ ).

$60 \mathrm{~N}$. So the total deviation of the vibration force which was propagated to the tractor body was nearly $120 \mathrm{~N}$.

Spectrum maps for the vibration force had peaks at $0.0 \mathrm{~Hz}$. But it is possible to neglect the existence of these peaks. Since the peaks were caused by the difference between the average level of the time continuous data for the vibration force and the zero level of it, the difference was not affected by the vibration characteristics itself. These spectrum maps (Fig. 3, 4) showed stable vibration force of the same value for the left side and right side in the experiment. 
On the other hand, spectrum map of the acceleration for forced frequency in the forward direction at the tractor's center of gravity showed the amplifier peaks at the forced frequency ranging from $3.0 \mathrm{~Hz}$ to $4.0 \mathrm{~Hz}$ (Fig. 5). Especially there were very small peaks at the forced frequency $1.0 \mathrm{~Hz}$ to $2.0 \mathrm{~Hz}$, and the data weren't affected by the noise. But the acceleration amplifier in the forward direction suddenly increased at the forced frequency ranging from $2.5 \mathrm{~Hz}$ to $3.0 \mathrm{~Hz}$ accompanied with the noise which occurred from the vibration of the tractor body. This tendency proved that the noise was greater as vibration level was higher. And the amplifier peaks of the noise didn't exhibit small values forced frequency greater than $8.0 \mathrm{~Hz}$.

Spectrum map of the acceleration for forced frequency in the vertical direction at the tractor's center of gravity showed the amplifier peaks at the forced frequency ranging from $7.0 \mathrm{~Hz}$ to $8.0 \mathrm{~Hz}$ (Fig. 6). On the other hand, the amplifier peaks which occured at forced frequency greater than $8.0 \mathrm{~Hz}$ showed the disorder related frequencies based on the forced frequency. Furthermore, these peaks showed the maximum peaks of this spectrum map, and showed the regular figure (line). The noise of spectrum map of the acceleration in the vertical direction was smaller than the noise of spectrum map in the forward direction.

Spectrum maps of the acceleration for forced frequency in the vertical direction at the tractor's front end and rear end are shown in Fig. 7 and Fig. 8. The petching acceleration was calculated by using these two accelerations. The peaks of the pitching direction of the tractor occured at the forced frequency of $3.3 \mathrm{~Hz}$ and $7.0 \mathrm{~Hz}$. The noise in these spectrum maps were much smaller than the noise in spectrum maps of the acceleration in the forward or the vertical direction.

These conclusions suggested that the nonlinear elements of the tractor didn't affect the vibration characteristics at the forced frequency less than $8.0 \mathrm{~Hz}$, but as the forced frequency was increased, the spectrum maps in the forward and the vertical direction showed some nonlinearity of the tractor vibration at the forced frequency ranging from $8.0 \mathrm{~Hz}$ to $10.0 \mathrm{~Hz}$.

\section{Phase projection and Poincare section}

Phase projection of the acceleration in the forward direction (forced frequency $3.3 \mathrm{~Hz}$ ) is shown in Fig. 10. This figure of phase projection was approximately a circle. As a result, the data indicated remarkable periodicity based on the forced frequency $(3.3 \mathrm{~Hz})$, and express the high reliability of the frequency response for the vibration characteristics.

Phase projections of the acceleration in the vertical direction (forced frequency $3.3 \mathrm{~Hz}, 5.3 \mathrm{~Hz}$ ) are shown in Fig, 11 and Fig. 13. These figures of phase projection were not the same as Fig. 10, and indicated that these data had more than two frequencies which were different from the forced frequency $(3.3 \mathrm{~Hz}$ or $5.3 \mathrm{~Hz})$. So the data showed a weak nonlinearity. However Poincare section of the data showed a periodicity based on the forced frequeycy (Fig. 12 and Fig. 14).

All accelerations of the time continuous data showed periodicity based on the forced frequency through Poincare section, however, the small amplitude of the acceleration exhibited nonlinearity on phase projection.

It is concluded that nonlinearity characteristics of the data are explained as fellows;

1) The deviation for the acceleration of most phase projections which exhibited the 
nonlinearity characteristics were small. Then the noise per signal ratio (N/S ratio) is universally high in this case, and the noise disorders the linearity characteristics of the data.

But when the data was converted to digital data from analog data, the low-pass filter (less than $10.0 \mathrm{~Hz}$ ) was used, therefore, it was difficult to conclude that the noise influenced to the nonlinearity characteristics.

2) Data sensibility for A/D converter was not enough to analyze the small level acceleration of the data. In our analysis method, sweep time was sufficient, but the accuracy of voltage analysis was still low.

3) It is not possible to judge whether the deviation of vibration force was proper for the analysis of the vibration characteristics of the tractor. Generally, the smaller the input value for the system which has the saturation characteristics is, the higher the level of the accuracy for the analysis is (Hirai and Ikeda, 1986). However, in this experiment, if the vibration force level was not enough to analyze the natural vibration characteristics based on the tractor dynamic model, then the data of the output acceleration measured at the center of gravity of the tractor would have nonlinearity.

So, before forced vibration experiment, the level of the vibration force should be sufficiently studied to measure the frequency response based on the tractor dynamic model.

\section{ACKNOWLEDGEMENTS}

We wish to thank Mr. Moses Frank Oduori for assistance with the English form of the manuscript.

\section{REFERENCES}

Collins, T. S. 1991 Loads in Tractor Linkage when Transporting Rear-Mounted Implements, Development of Modelling and Measurement Techniques, J. agric. Engng Res. 49: 165-188

Dimarogonas, Andrew D. and Sam Haddad 1992 Vibration for Engineers Prentice-Hall International (USA), pp. 635-637

Goldman, David E. and Henning E. von Gierke 1960 The Effects of shock and Vibration on Man, Lecture and Review Series (Navel Medical Research Institute, Bethesda, Marryland 8) (USA), 60 (3)

Hirai, K. and M. Ikeda 1986 Analysis of Nonlinear Control System, Ohmu-sha Tokyo, pp. 2-4

Sakai, J., R. Noguchi and 0. Kinoshita 1991 Vibration Analysis of Riding Tractor by using MATLAB Software, Kyushu Branch J. of JSAM, 40: 35-39

Sakai, K., Y. Toyokawa, S. Nambu, S. Mizushima, M. Takai and S. Hata 1992 Non- linear Dynamics and Chaos in Agricultural Vehicle Systims, Proceedings of the 4th regional North American Meeting, Sacramento CA (USA)

Sunahara, Y. 1982 Chaos, Strange Attractors and Erratic Motion, The Journal of the Insitute of Electronics Communication Engineers of Japan, 65 (3): 289 - 295

Thompson, J. M. T. and H. B. Stewart (translated by Toshimitsu MUSYA, Sumihisa HASH1 GUCHI 1988 Nonlinear Dynamics and Chaos, Ohmu-sha Tokyo, pp. 1-28 